
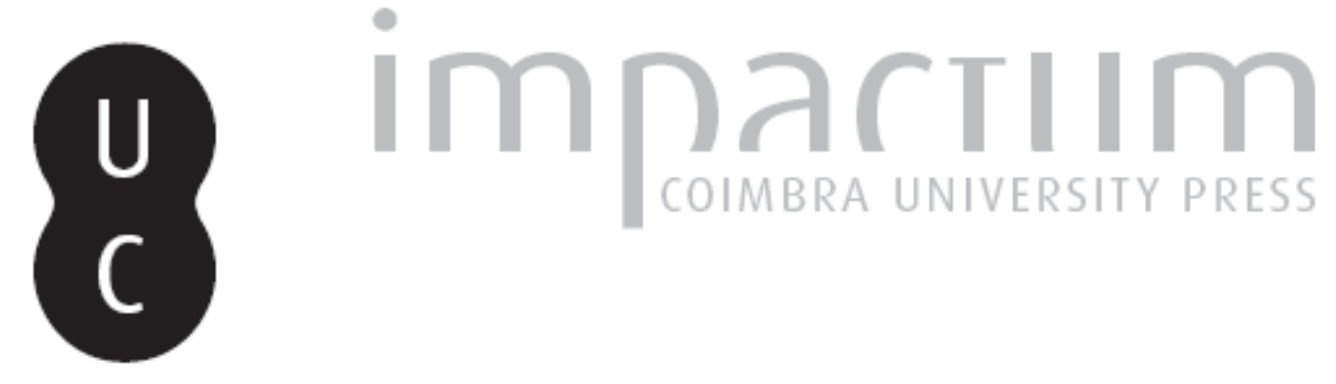

\title{
Fernando Pessoa e o movimento racionalista: um estudo a partir do espólio
}

Autor(es): Ribeiro, Nuno

Publicado por: Imprensa da Universidade de Coimbra

URL persistente:

URI:http://hdl.handle.net/10316.2/42843

DOI:

DOI:http://dx.doi.org/10.14195/0872-0851_49_6

Accessed : $\quad$ 26-Apr-2023 08:36:53

A navegação consulta e descarregamento dos títulos inseridos nas Bibliotecas Digitais UC Digitalis, UC Pombalina e UC Impactum, pressupõem a aceitação plena e sem reservas dos Termos e Condições de Uso destas Bibliotecas Digitais, disponíveis em https://digitalis.uc.pt/pt-pt/termos.

Conforme exposto nos referidos Termos e Condições de Uso, o descarregamento de títulos de acesso restrito requer uma licença válida de autorização devendo o utilizador aceder ao(s) documento(s) a partir de um endereço de IP da instituição detentora da supramencionada licença.

Ao utilizador é apenas permitido o descarregamento para uso pessoal, pelo que o emprego do(s) título(s) descarregado(s) para outro fim, designadamente comercial, carece de autorização do respetivo autor ou editor da obra.

Na medida em que todas as obras da UC Digitalis se encontram protegidas pelo Código do Direito de Autor e Direitos Conexos e demais legislação aplicável, toda a cópia, parcial ou total, deste documento, nos casos em que é legalmente admitida, deverá conter ou fazer-se acompanhar por este aviso.

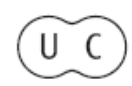




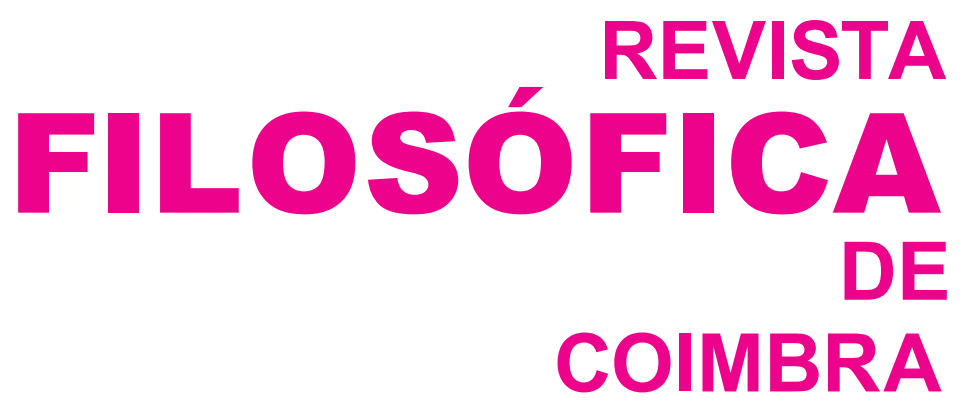

vol. 25 - número 49 - março 2016

vol. 25 - número 49 - março 2016

Fundação Eng. António de Almeida

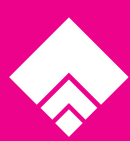




\title{
FERNANDO PESSOA E O MOVIMENTO RACIONALISTA - UM ESTUDO A PARTIR DO ESPÓLIO
}

\author{
FERNANDO PESSOA AND THE RATIONALIST MOVEMENT
}

- A STUDY FROM HIS ESTATE

NUNO RIBEIRO*

Resumo: $\mathrm{O}$ presente artigo tem por objectivo mostrar as considerações de Fernando Pessoa sobre o movimento racionalista, tendo em conta os escritos filosóficos do espólio deste autor. Com efeito, no espólio de Pessoa encontramos inúmeros escritos póstumos destinados a um ensaio sobre a natureza e o sentido do racionalismo, que são o reflexo de múltiplas leituras filosóficas realizadas por este pensador. Assim, tendo por base um estudo sistemático da evolução dos escritos filosóficos de Fernando Pessoa sobre o racionalismo, pretendemos mostrar a reapropriação pessoana de algumas das linhas fundamentais do pensamento racionalista.

Palavras-chave: Fernando Pessoa, filosofia, movimento racionalista, espólio.

\begin{abstract}
This article intends to show Fernando Pessoa's considerations about the rationalist movement, taking into consideration the philosophical writings present in his archive. Indeed, in Pessoa's archive one finds several posthumous writings designed for an essay on the nature and meaning of rationalism, which reflect the multiple philosophical readings carried out by
\end{abstract}

Résumé: Cet article vise à montrer les considérations de Fernando Pessoa sur le mouvement rationaliste, en tenant compte des écrits philosophiques de l'archive de cet auteur. En effet, dans l'archive de Pessoa on trouve nombreux écrits posthumes destinés à un essai sur la nature et le sens du rationalisme, qui reflètent de multiples lectures philosophiques de ce penseur. Ainsi, sur la base

* Universidade Federal de São Carlos, Departamento de Filosofia e Metodologia das Ciências. Este trabalho foi realizado no decurso de uma pesquisa de pós-doutorado com o apoio financeiro da FAPESP, Fundação de Amparo à Pesquisa do Estado de São Paulo, (Processo n ${ }^{\mathrm{o}}: 2012 / 12102-0$ ), no âmbito do projecto temático FAPESP número: 2012/50005-6; nuno.f.ribeiro@sapo.pt 
this thinker. Thus, based on the systematic study of the development of Fernando Pessoa's philosophical writings on rationalism, we intend to show Pessoa's appropriation of some of the main lines of the rationalist movement.

Keywords: Fernando Pessoa, phi losophy, rationalist movement, archive. d'une étude systématique de l'évolution des écrits philosophiques de Fernando Pessoa sur le rationalisme, nous avons l'intention de montrer la réappropriation que Pessoa fait de certaines des lignes principales de la pensée rationaliste.

Mots-clés: Fernando Pessoa, philosophie, mouvement rationaliste, archive.

The strength of rationalism is in its narrowness for all strength is a narrowness. It leaves us ever humble before the infinite remainder.

Fernando Pessoa $\left(\mathrm{BNP} / \mathrm{E} 3,15^{2}-64^{\mathrm{r}}\right)^{1}$

\section{1 - As leituras e o desenvolvimento dos escritos sobre o racionalismo}

O interesse de Pessoa pelo movimento racionalista é suficientemente comprovado pelas listas de leitura deixadas no seu espólio e pelos livros presentes na sua biblioteca particular. Numa lista de leituras presente num caderno, datável de 1906, atribuído a Charles Robert Anon, ${ }^{2}$ uma personalidade do universo pré-heteronímico pessoano, encontramos inúmeras referências a livros sobre o racionalismo, como The Age of Reason de Thomas Paine, ${ }^{3}$ Root Principles in Rational and Spiritual Things de Thomas Child ${ }^{4}$ e Letters on Reasoning de John Mackinnon Robertson, ${ }^{5}$ referências também mencionadas num caderno de leituras filosóficas com a data de Setembro de

1 A indicação BNP/E3 refere-se ao espólio de Fernando Pessoa, catalogado na Biblioteca Nacional de Portugal [BNP] como Espólio 3 [E3]. Para transcrição de documentos do espólio de Fernando Pessoa citados ao longo deste artigo utilizamos a seguinte chave dos símbolos:

$X X X X X X$ - sublinhado

$|\mathrm{XXXX}|$ - segmento dubitado pelo autor

$\square-$ espaço deixado em branco pelo autor

2 Cf.: BNP/E3, 13A - 1-20; Fernando Pessoa, Cadernos - Tomo I, edição de Jerónimo Pizarro (Lisboa: Imprensa Nacional-Casa da Moeda, 2009), 269-290.

3 Cf:: BNP/E3, $13 \mathrm{~A}-8^{\mathrm{r}}$.

4 Cf.: BNP/E3, $13 \mathrm{~A}-9^{\mathrm{r}}$.

5 Cf.: BNP/E3, $13 \mathrm{~A}-8^{\mathrm{r}}$. 
1906 e pertencente ao pré-heterónimo Alexander Search, ${ }^{6}$ que se constitui igualmente como um testemunho do interesse pela corrente de pensamento racionalista. Numa agenda comercial com a data de $1911,{ }^{7}$ que é simultaneamente um caderno de apontamentos e lista de leituras, encontramos, por exemplo, a seguinte referência: "Robertson (J.M.): Rationalism". ${ }^{8}$ Ainda em outra lista de leituras vemos a seguinte menção: "Alfred William Benn: History of English Rationalism in the Nineteenth Century." As referências e menções ao movimento racionalista encontram-se presentes nas mais diversas listas de leitura dispersas ao longo do espólio de Fernando Pessoa. Mas o interesse de Pessoa pela bibliografia relativa ao racionalismo não se circunscreve aos títulos presentes nas listas do seu espólio. Para além das entradas presentes nas suas listas de leitura, encontramos ainda na Biblioteca Particular de Pessoa inúmeras obras de e sobre o racionalismo de autores como o já citado John Mackinnon Robertson, de H. G. Wells e de Hypatia Bradlaugh Bonner. ${ }^{10}$ Do interesse de Fernando Pessoa pelo movimento racionalista e das leituras que daí advieram resultaram inúmeros escritos filosóficos. Com efeito, os escritos sobre o racionalismo são talvez os mais extensos de entre todos aqueles que foram redigidos por Fernando Pessoa.

No espólio deste autor encontramos diversas séries ou núcleos de documentos sobre o racionalismo cujos títulos fazem menção ao movimento racionalista. Esses títulos são: 1) Ensaio sobre a Natureza e o Sentido do Racionalismo [Essay on the Nature and Meaning of the Rationalism], que corresponde, muito provavelmente, ao primeiro título completo concebido por Pessoa para uma obra sobre o racionalismo; 2) Racionalismo [Rationalism] ou rat. ${ }^{m}$, que é possivelmente apenas uma abreviatura do título completo;

${ }^{6}$ Cf.: BNP/E3 - 144H. As referências do caderno de Search são: The Age of Reason de Thomas Paine [BNP/E3, 144H - 26v: "15. "The Age of Reason'"], Root Principles in Rational and Spiritual Things de Thomas Child [BNP/E3, 144H - 9r: "3. Child (T): 'RootPrinciples in Rational and spiritual things."'] e Letters on Reasoning de John Mackinnon Robertson [BNP/E3, 144H - 28v: "19. 'Letters on Reasoning."'].

7 Cf.: BNP/E3, 144D 2 .

$8 \mathrm{BNP} / \mathrm{E} 3,144 \mathrm{D}^{2}-86^{\mathrm{r}}$.

$9 \mathrm{BNP} / \mathrm{E} 3,48-50^{\mathrm{r}}$.

10 José Barreto, em anexo ao seu artigo Fernando Pessoa racionalista, livre-pensador e individualista: a influência liberal inglesa [cf.: José Barreto, "Fernando Pessoa racionalista, livre-pensador e individualista: a influência liberal inglesa", in: A Arca de Pessoa: Novos Ensaios, org. Jeronimo Pizarro, Steffen Dix (Lisboa: ICS, 2007), 109-127], apresenta uma extensa lista de livros da Biblioteca Particular de Fernando Pessoa sobre o racionalismo, para a qual remetemos o leitor. No entanto, como teremos a oportunidade de mostrar, Pessoa inclui sob a denominação de racionalismo outros autores que não são indicados nessa lista. Essa exclusão talvez se deva à circunstância de esse artigo deixar de fora os escritos filosóficos sobre o racionalismo. 
3) Racionalismo Liberal [Liberal Rationalism], que poderá ser interpretado como um capítulo do Ensaio sobre o racionalismo; 4) Um exame do Racionalismo [An examination of Rationalism], que é certamente o título de um texto autónomo. Para além das séries de documentos encimadas por estes títulos encontramos ainda páginas autónomas sem qualquer título, mas cujo conteúdo nos permite reagrupá-las no âmbito do Ensaio sobre a Natureza e o Sentido do Racionalismo [Essay on the Nature and Meaning of Rationalism]. ${ }^{11}$ Digna de nota é ainda a ficha biográfica de Alexander Search em O Livro da Transformação [The Transformation Book], onde se encontra listado o título A Filosofia do Racionalismo ["The Philosophy of Rationalism"] ${ }^{12}$, que poderá ser interpretado como um dos títulos pensados por Pessoa para o ensaio sobre o racionalismo. No entanto, a despeito da diversidade de escritos e de títulos para os vários núcleos de textos sobre o racionalismo, o projecto da redacção de um ensaio sobre o racionalismo tem um corpus central. Esse corpus central encontra-se nas séries de documentos encimadas pelos títulos Ensaio sobre a Natureza e o Sentido do Racionalismo [Essay on the Nature and Meaning of Rationalism] e Racionalismo [Rationalism] (ou Rat. ${ }^{m}$ ), relativamente aos quais os demais escritos são desenvolvimentos ocasionais e subsidiários. Assim, o desenvolvimento desse corpus central é constituído por três etapas.

a) A primeira etapa corresponde a uma série de dois documentos, um com o título Ensaio sobre a Natureza e o Sentido do Racionalismo [Essay on the Nature and Meaning of Rationalism] [BNP/E3, 155 - 79], outro apenas intitulado Racionalismo [Rationalism] [BNP/E3, $\left.15^{5}-78\right]$, escritos entre 1906 e 1907, correspondentes ambos a apontamentos e esquemas iniciais para a elaboração de uma obra sobre o racionalismo.

b) A segunda etapa corresponde a dois núcleos de documentos manuscritos intitulados Racionalismo [Rationalism] (ou a abreviatura Rat. $^{m}$ ) [BNP/ E3, $15^{3}-37-45$ e $\left.133 \mathrm{~F}-64-64 \mathrm{a}\right]$. Estes documentos, escritos em meados de 1908, têm um conteúdo bastante mais desenvolvido do que os documentos correspondentes à primeira etapa e contêm já inúmeras passagens que viriam a ser reintegradas nos documentos correspondentes à terceira etapa;

c) A terceira etapa corresponde a uma série de nove documentos datiloscritos, escritos entre o final de 1908 e 1909, com algumas anotações e

11 Para efeitos de consulta dos diversos textos sobre o racionalismo remetemos para nossa edição dos Philosophical Essays de Fernando Pessoa, com a seguinte referencia: Fernando Pessoa, Philosophical Essays: a critical edition, edition, notes and introduction by Nuno Ribeiro, afterword by Paulo Borges, (New York: Contra Mundum Press, 2012).

12 Cf.: Fernando Pessoa, The Transformation Book - or Book of Tasks, edition, notes and introduction Nuno Ribeiro \& Cláudia Souza (New York: Contra Mundum Press, 2014), 4. 
acrescentos manuscritos [BNP/E3, $15^{2}-62$ a 70]. Esta série de documentos corresponde a um desenvolvimento e elucidação dos documentos correspondentes à segunda etapa e, por conseguinte, de todo o projecto que é esboçado a partir dos esquemas e apontamentos do núcleo de documentos da primeira etapa, sendo, por conseguinte, a versão mais acabada, embora não inteiramente concluída, do Ensaio sobre a Natureza e o Sentido do Racionalismo [Essay on the Nature and Meaning of Rationalism].

Estas três etapas correspondem, deste modo, a um crescendo no que respeita à forma, ao tipo de material e ao conteúdo, começando com um conjunto de textos manuscritos correspondentes a um conjunto de apontamentos bastante fragmentários e incipientes e que termina numa série de textos datiloscritos de conteúdo bastante mais desenvolvido. Talvez se possam considerar como pertencentes à terceira etapa de desenvolvimento do corpus central do projecto de redacção de um ensaio sobre o racionalismo os seguintes dcumentos escritos também entre o final de 1908 e 1909: 1) uma página datiloscrita sem título, que começa da seguinte forma: "Existem dois racionalismos." [BNP/E3, 55G - 24r: "There are two rationalisms." ]; 2) três folhas manuscritas também sem título [BNP/E3, $\left.15^{1}-45-47\right]$; 3) o texto intitulado "Racionalismo Liberal" ["Liberal Rationalism"] [BNP/E3, $15^{5}$ 19] que, como dissémos, poderá ser interpretado como um capítulo do ensaio sobre o racionalismo. No entanto, Pessoa não nos deixa qualquer indicação a esse respeito, pelo que a inclusão dessa página nos textos da terceira etapa apenas pode ser feita a título hipotético.

\section{2 - A imagem pessoana do racionalismo}

Apesar de Pessoa ter tomado conhecimento do racionalismo, sobretudo, através da leitura dos livros ingleses associados à Rationalist Press Association, ${ }^{13}$ viria a ser Kant a figura principal para a constituição da imagem pessoana da corrente racionalista. Num texto da segunda etapa do desenvolvimento do ensaio sobre o racionalismo de Fernando Pessoa lemos:

O Racionalismo é expressamente raro e tendencialmente comum. A literatura do pensamento (exceptuando a Grécia) contém poucas expressões do racionalismo. Se considerarmos que Kant é o típico racionalista e quão poucos pensadores se assemelham a Kant, compreenderemos isto.

13 Com efeito, como nos mostra José Barreto no seu artigo Fernando Pessoa - racionalista, livre-pensador e individualista: a influência liberal inglesa, muitas das leituras pessoanas da juventude sul-africana e lisboeta relativas ao racionalismo foram veiculadas por obras divulgadas a baixo custo pela Rationalist Press Association, algumas das quais constam na sua Biblioteca Particular. 
[Rationalism is expressedly rare and tendentially common. The literature of thought (apart from Greece) contains few expressions of rationalism. If we consider that Kant is the typical rationalist, and how few thinkers resemble Kant, we will understand this. ${ }^{14}$

Em outro texto, que poderá ser considerado como a continuação deste, lemos ainda:

A criação kantiana não só da distinção entre o sujeito e o objecto e entre o númeno e o fenómeno, mas também de uma das principais distinções do racionalismo - a que distingue a razão pura e a prática.

[Kant's creation not only of the distinction between the subject and the object and between noumenon and phainomenon, but also of one of the main distinctions of rationalism - the one between pure and practical reason. ${ }^{15}$

Com efeito, estes dois trechos da segunda etapa de desenvolvimento dos textos pessoanos sobre o racionalismo, mostram não só a importância da figura de Kant para a elaboração do pensamento filosófico deste autor português, mas também o modo como Fernando Pessoa, na elaboração do seu pensamento filosófico, se reapropria dos conceitos da tradição filosófica para construir o seu próprio pensamento. Pessoa apresenta-nos Kant como o típico racionalista, e as distinções kantianas entre númeno e fenónemo e entre razão pura e razão prática como as principais distinções do racionalismo. Esta atitude relativa à importância da filosofia kantiana para definição da imagem pessoana do racionalismo viria também a ganhar expressão nos textos da terceira etapa da elaboração do ensaio sobre o racionalismo, como se pode ver no seguinte trecho:

A grande distinção kantiana entre a razão pura e a prática..... Ele foi o maior racionalista que o mundo jamais viu pensar sobre esse assunto. Ele preparou a sua salvação de toda a razão naquela calma Koenigsberg, apenas com a lei moral e as estrelas.

[Kant's great distinction between pure and practical reason...... He was the greatest rationalist the world has ever had thinking upon it. He worked out his own salvation of all reason in that quiet Koenigsberg, alone with moral law and the stars.] $]^{16}$

Assim, partindo da figura e dos conceitos da filosofia Kantiana, Pessoa define o racionalismo como uma atitude metodológica assente em dois princípios: 1) que apenas pode ser considerado como facto aquilo que a razão

\footnotetext{
14 BNP/E3, $15^{3}-40^{\mathrm{r}}$; cf.: Pessoa, Philosophical, 148-149.

15 BNP/E3, $15^{3}-41^{\text {r }}$; cf.: Pessoa, Philosophical, 149.

16 BNP/E3 - 15² - 66 ; cf.: Pessoa, Philosophical, 10.
} 
pode reduzir pela experiência a um dado científico; 2) que para lá dos factos científicos nada pode racionalmente ser afirmado, nem como verdadeiro, nem como falso. É isso que lemos na seguinte passagem:

O racionalismo sustenta que as únicas coisas que podem ser afirmadas como factos são aquelas que reduzem a experiência pela razão à coordenação chamada ciência. O racionalismo sustenta que todas as coisas, para além disto, são simplesmente desconhecidas, ou até agora desconhecidas; mas não afirma nem que não podem ser conhecidas e ainda menos que são falsas. Pois o que não pode ser aprovado também não pode ser desaprovado.

[Rationalism holds that the only things that can be affirmed as facts are those which reduce experience by reason to the coordination called science. Rationalism holds that all things outside this are simply unknown, or as yet unknown; but it does not affirm either that they are unknowable and still less that they are false. For what cannot be proved cannot also be disproved.] $]^{17}$

Nos textos de Pessoa sobre o racionalismo, a noção de facto desempenha o mesmo papel que a noção de fenómeno na filosofia de Kant, o que muito provavelmente leva Fernando Pessoa a considerar a distinção entre númeno e fenómeno como uma das fundamentais distinções do pensamento racionalista. Na Crítica da Razão Pura, Immanuel Kant leva a cabo o levantamento das condições de possibilidade de conhecimento. Esse levantamento visa averiguar se é ou não possível a constituição da metafísica como ciência. Aquilo que Kant mostra é que para lá do fenómeno não é possível ciência e que, por conseguinte, a metafísica, tendo por objecto algo que ultrapassa o domínio do fenómeno, não é possível como ciência. Assim, Kant reconduz toda a esfera do conhecimento ao domínio do fenómeno e às leis que regem o mundo dos fenómenos. A redução aos factos, presente nos textos pessoanos sobre o racionalismo, tem o mesmo alcance que a redução kantiana do conhecimento ao domínio dos fenómenos. Também em Pessoa existe uma recusa em afirmar a possibilidade da metafísica como ciência. É isso que, muito provavelmente, leva Pessoa a tecer a seguinte consideração nas primeiras linhas do fragmento intitulado Racionalismo Liberal [Liberal Rationalism]:

Existem dois erros que podem ser cometidos a este respeito. Um é fazer da metafísica uma ciência, o outro fazer da ciência uma metafísica.

[There are two errors that may be committed in this respect. One is to make metaphysics a science, the other to make science a metaphysics. $]^{18}$

Com efeito, nos textos de Pessoa sobre o racionalismo encontramos a recondução de todo o conhecimento apodíctico ao domínio dos factos cien-

17 BNP/E3 - $15^{2}-62^{\text {r }}$; cf.: Pessoa, Philosophical, 2.

18 BNP/E3, $15^{5}$ - 19r; cf.: Pessoa, Philosophical, 23. 
tíficos e a suspensão de toda a apodicticidade no que respeita aos dados que ultrapassam o domínio dos factos. A redução aos factos é, desse modo, animada por aquilo que Pessoa denomina de espírito científico, que este autor define do seguinte modo:

O espírito científico significa três coisas: (1) considerar como de facto (ou, pelo menos, provisoriamente) verdadeiro apenas aquelas leis ou factos que tenham sido sujeitos a um teste objectivo, que alguém, dada a cultura, os instrumentos e a oportunidade, possa igualmente aplicar; (2) considerar como de facto (ou, pelo menos, provisoriamente) falsas as doutrinas ou pseudo-factos que directamente contradigam tais leis ou factos e sejam insusceptíveis não por natureza, mas por declaração, de uma prova objectiva ou, sendo susceptíveis disso, não estão ou ainda não foram conduzidas a isso; (3) considerar como desconhecidas no que respeita à sua verdade aquelas teorias ou ideias que, sendo de uma natureza completamente incomensurável com as leis e factos que podem ser verificados objectivamente, são, em virtude da sua própria natureza, insusceptíveis de prova objectiva.

[The scientific spirit means three things: (1) the holding as actually (or, at least, provisionally) true only those laws or facts which have been subjected to an objective test, which anyone, given the culture, the instruments and the opportunity, may equally well apply; (2) the holding as actually (or, at least, provisionally) false of the doctrines or pseudo-facts which directly contradict such laws or facts and are either insusceptible not by nature, but by statement, of objective proof or, being susceptible of it, are not or have not been brought to it; (3) the holding as unknown as to their truth those theories or ideas which, being of a nature wholly incommensurable with the laws and facts which can be verified objectively, are, by that very nature, insusceptible of objective proof.] ${ }^{19}$

Assim, todos estes indícios espalhados ao longo dos diversos escritos relativos ao racionalismo permitem-nos delinear uma imagem pessoana do racionalismo de cariz eminentemente kantiano.

No entanto, Pessoa estabelece a distinção entre dois tipos de racionalismo. Com efeito, numa página autónoma, que poderá ser considerada como um prolongamento do corpus central do ensaio sobre o racionalismo, este autor fala-nos de um racionalismo inferior e de um racionalismo superior. Lemos precisamente isso na seguinte passagem:

Existem dois racionalismos. Existe um racionalismo inferior, ou fetichista, que é o daqueles a que comummente se chama racionalistas; e existe um racionalismo superior. Ambos acreditam - no fundo isso é, como no fundo de tudo o resto, uma crença inverificável - que a razão é tudo o que temos, ou o melhor que temos, para investigar a verdade. Os dois diferem no que

19 BNP/E3 - 15² - 68 ; cf.: Pessoa, Philosophical, 13-14. 
consideram que deve ser investigado como verdade. O racionalismo inferior é ainda refém do velho mito metafísico - de que a razão pode alcançar conclusões metafísicas. O racionalismo superior, baseado na premissa de que todo o conhecimento vem dos sentidos, e de que a razão não é um sentido, não pode admitir a possibilidade de a razão ser mais do que algo que articula os dados dos sentidos; e considerando que não existem nenhuns sentidos conhecidos (a não ser que os místicos estejam correctos, o que não podemos verificar para satisfação universal) que forneçam dados metafísicos, a razão é impotente para chegar a uma conclusão no que respeita aos fundamentos do ser.

[There are two rationalisms. There is a lower, or fetichistic, rationalism which is that of rationalists commonly so called, and commonly so calling themselves; and there is a higher rationalism. Both believe - at bottom this is, like the bottom of everything else, an unverifiable belief - that reason is all that we have, or the best we have, to investigate truth. The two differ as to what they consider the truth that can be investigated. The lower rationalism is still captive of the old metaphysical myth - that reason can reach metaphysical conclusions. The higher rationalism, basing on the premise that all knowledge comes from the senses, and that reason is not a sense, cannot admit the possibility of reason more than sifting the data of the senses; and as there are no known senses (unless the mystics are right, which we cannot verify to universal satisfaction) which supply metaphysical data, reason is powerless to arrive at any conclusion as to the fundamentals of being. $]^{20}$

De acordo com este trecho, o racionalismo inferior reincidiria ainda no mito metafísico de que pela razão seria possível alcançar alguma verdade ou conhecimento seguro no domínio da investigação metafísica. Assim, o racionalismo inferior cairia no erro de fazer da metafísica uma ciência. O racionalismo superior, por outro lado, seria um racionalismo liberto do mito metafísico, isto é, liberto da confusão entre metafísica e a ciência. O racionalismo superior constitui-se, desta forma como um racionalismo esclarecido, por outras palavras, um racionalismo onde a crítica da razão é levada à recondução de todo o conhecimento possível ao domínio dos factos da ciência e à eliminação, pelo menos a título provisório, da possibilidade da afirmação da metafísica como ciência. É neste sentido que Pessoa apresenta Kant como o típico racionalista.

\section{3 - A admissão racionalista de todas as crenças}

A recondução racionalista de todo o conhecimento ao domínio dos factos e das leis que regem os factos conduz a uma demarcação entre a esfera do conhecimento e a esfera da fé. $\mathrm{Na}$ esfera do conhecimento, como vimos,

20 BNP/E3, 55G - 24r; cf.: Pessoa, Philosophical, 19-20. 
apenas podem ser considerados factos aquelas coisas ou acontecimentos que podem ser reduzidos pela razão à ciência. Com efeito, a redução racionalista da esfera do conhecimento aos factos leva a uma consecutiva redução da esfera dos objectos do conhecimento. Lemos, nesse sentido, a seguinte passagem (que serve de epígrafe a este artigo):

A força do racionalismo reside na sua estreiteza pois toda a força é uma estreiteza. Deixa-nos sempre humildes perante o restante infinito.

[The strength of rationalism is in its narrowness for all strength is a narrowness. It leaves us ever humble before the infinite remainder.] ${ }^{21}$

No entanto, a par de uma redução da esfera do conhecimento, o racionalismo opera um alargamento no plano da fé. Se a esfera do conhecimento é caracterizada por uma estreiteza no que respeita àquilo que pode ser considerado como facto, a esfera da fé é caracterizada por uma ruptura com essa estreiteza. Para lá do domínio dos factos todas as convicções e crenças são possíveis. Lemos justamente isso, no texto relativo aos dois racionalismos, a propósito do racionalismo superior:

Todas as fés, por mais absurdas que possam parecer, ou contraditórias, são, por conseguinte, possíveis; não podem ser denunciadas como falsas; devem simplesmente ser admitidas como probabilidades que nunca poderão ser verificadas. Isto conduz a uma tolerância sem limites.

A atitude do racionalismo superior tem como símbolo a célebre anedota relativa a Baudelaire. Um marinheiro seu amigo, que havia acabado de regressar de uma longa viagem colonial, mostrou-lhe um fetish que trouxera; mostrou-lho com repulsa pelo objecto de madeira, o surpreendente ídolo de uma raça humana. E, como se pretendesse, após o mostrar, atirá-lo com repulsa para um canto, Baudelaire agarrou-lhe o braço. "Para!", disse, "E se for o verdadeiro Deus?" - Et si c'etait le vrai Dieu? - Isto é o racionalismo superior em essência e tom.

[All faiths, however absurd they may seem, or contradictory, are therefore possible; they cannot be denounced as false; they must simply be let live as probabilities that never can be verified. This leads to tolerance without an effort. The attitude of higher rationalism receives its symbol in that celebrated anecdote, which is related of Baudelaire. A naval officer, a friend of his, who had just returned from a long colonial voyage, was showing him a fetish he had brought back; he showed him with disgust that wooden object, the astonishing idol of a human race. And, as he, after having shown it, was going to throw it in disgust into a corner, Baudelaire laid sudden hands upon his arm. "Stop!" he said, "What if it were the true God?" - Et si c'etait le vrai Dieu? - This is the higher rationalism, both in essence and in tone.] $]^{22}$

21 BNP/E3, 15²-64ri ; cf.: Pessoa, Philosophical, 6.

22 BNP/E3, 55G - 24r; cf.: Pessoa, Philosophical, 20. 
A admissão racionalista de todas as crenças conduz, desta forma, a uma demarcação entre a atitude racionalista e o ateísmo, o agnosticismo e o cepticismo. O agnosticismo e o ateísmo são, de acordo com os textos sobre o racionalismo, subsidiários de um mesmo fundo comum, ainda que sob aspectos diferentes. Quer a atitude ateia, quer a agnóstica pretendem assumir-se como formas de descrença. No entanto, apesar de se pretenderem assumir como tal, persiste em ambas uma forma de crença camuflada de descrença. $\mathrm{O}$ ateísmo, pretendendo afirmar-se como uma atitude de descrença - a descrença em Deus - fica, porém, preso a outra crença, isto é, a crença na não existência de Deus. Com efeito, lemos num texto da terceira etapa do desenvolvimento do ensaio relativo ao racionalismo:

Por esta razão o ateísmo não é de todo racionalismo, e nenhum ateu se pode considerar como racionalista, a não ser que ignore o sentido do racionalismo, do ateísmo, ou de ambos. A verdade é que o ateísmo não é uma forma de descrença, mas antes de crença. Supõe-se comummente que um ateu é um homem que não acredita na existência de Deus. Isto está errado, porque ele não é assim tão negador. É um homem que acredita na existência do não-Deus. Daí a sua positividade, a sua alegria e aquela fervorosa fé de um militante não cristão.

[For this reason atheism is not rationalism at all, and no atheist can describe himself as a rationalist unless he ignores the meaning of rationalism, of atheism, or of both. The truth is that atheism is not a form of disbelief, but of belief. It is commonly supposed that an atheist is a man who does not believe in the existence of God. This is wrong, for he is not so negative. He is a man who believes in the existence of not-God. Hence his positiveness, his happiness, and that buoyant faith of a militant unchristian. $]^{23}$

O agnosticismo pretende, por outro lado, assumir-se como uma atitude de suspensão da crença relativamente a todas aquelas coisas que ainda são desconhecidas. No entanto, apesar de advogar a suspensão da crença, a atitude agnóstica fica ainda refém da convicção de que o desconhecido é incognoscível. Lemos justamente isso na seguinte passagem:

Nem se pode dizer que o racionalismo e o agnosticismo são a mesma coisa. $\mathrm{O}$ agnosticismo implica a afirmação directa de que o desconhecido é incognoscível. O racionalismo não pode afirmar que o desconhecido é de tal forma conhecido que possa ser considerado incognoscível.

[Neither can it be said that rationalism and agnosticism are the same thing. Agnosticism directly implies the affirmation that the unknown is unknowable. Rationalism cannot say of the unknown that it is so far known as to be unknowable.] ${ }^{24}$

23 BNP/E3, $15^{2}-62^{\text {r }}$; cf.: Pessoa, Philosophical, 2-3.

24 BNP/E3, $15^{2}-62^{\text {r }}$; cf.: Pessoa, Philosophical, 3-4. 
A demarcação da atitude racionalista face ao ateísmo e ao agnosticismo poderia levar a crer que o racionalismo adoptaria uma postura céptica perante as questões relativas ao mundo, à realidade e ao problema do conhecimento. Contudo, nos textos relativos ao racionalismo encontramos uma diferenciação entre a atitude céptica e a atitude racionalista. O céptico adopta uma atitude de inteira descrença mesmo perante a razão. $\mathrm{O}$ racionalista acredita na razão, isto é, na capacidade de encontrar dados científicos no domínio dos factos, como podemos ler no seguinte trecho:

O cepticismo também pode ser confundido com o racionalismo. Mas o céptico, se o for realmente, não tem nenhuma crença; o racionalista acredita na razão. Até certo ponto, o racionalista, no que respeita a razão, é um crente. É porque o céptico não é um crente que se destrói a si próprio: o cepticismo, como em Pascal, sempre foi a antecâmara do misticismo.

[Scepticism may also be confounded with rationalism. But the sceptic, if he really be one, has no belief at all; the rationalist does believe in reason. To a certain extent, as far as reason, the rationalist is a believer. As a matter of fact, he is wholly a believer. It is because the sceptic is not a believer that he destroys himself: scepticism, as in Pascal, was ever the fore-prey of mysticism. $]^{25}$

A distinção entre racionalismo, ateísmo, agnosticismo e cepticismo é um dos momentos da admissão racionalista de todas as crenças. $\mathrm{O}$ ateísmo e o agnosticismo são ambos formas de crença revestidas de descrença. O cepticismo é uma forma de descrença absoluta. O racionalismo é uma atitude de crença na razão no domínio dos factos e de admissão de todas as crenças no domínio da fé. Porém, a admissão racionalista de todas as crenças pressupõe uma alteração do conceito de realidade. Para o racionalista a realidade não se circunscreve à mera realidade designada como exterior. Também o plano interior, isto é, a idealidade, se constitui como uma forma de realidade. A idealidade também se constitui como um domínio de factos, isto é, dos factos interiores. A seguinte passagem do núcleo da terceira etapa do corpus central do racionalismo constitui-se como um testemunho disso:

A realidade não é apenas pedras e plantas, com uma porção de animais em movimento. Também é os sonhos, as visões, as experiências místicas. Cristo pode não ser real enquanto realidade, mas tem sido real como idealidade. Para o realista, que é o racionalista, isso é tão suficiente quanto as estrelas. $\mathrm{O}$ ideal que os homens amaram é tão real quanto as mulheres que os homens amaram, pois o amor é algo real.

[Reality is not only stones and plants, with a moving sprinkling of animals. It is also the dreams, the visions, the mystical experiences, of the substance

25 BNP/E3, $15^{2}-63^{\text {r }}$; cf.: Pessoa, Philosophical, 4. 
and passing of mankind. Christ may not be real as reality, but has been real as an ideality. For the realist, who is the rationalist, that is as enough as the stars. The ideal men have loved is as real as the woman men have loved, for the love is the one actual thing. $]^{26}$

Assim, a transfiguração da noção de realidade permite não só a admissão de todas as crenças, mas também a afirmação da realidade dessas crenças, se não como algo que remete para uma realidade exterior, pelo menos enquanto realidade ideal.

\section{REFERÊNCIAS BIBLIOGRÁFICAS}

Barreto, José, "Fernando Pessoa racionalista, livre-pensador e individualista: a influência liberal inglesa", in: A Arca de Pessoa: Novos Ensaios, org. Jeronimo Pizarro, Steffen Dix. Lisboa: ICS, 2007, 109-127.

Pessoa, Fernando, Cadernos - Tomo I, edição de Jerónimo Pizarro. Lisboa: Imprensa Nacional-Casa da Moeda, 2009.

Pessoa, Fernando, Espólio de Fernando Pessoa - Inventário (BN. Esp. E3). Lisboa: Biblioteca Nacional de Portugal, 1986.

Pessoa, Fernando, Philosophical Essays: a critical edition, edition, notes and introduction by Nuno Ribeiro, afterword by Paulo Borges. New York: Contra Mundum Press, 2012.

Pessoa, Fernando, The Transformation Book - or Book of Tasks, edition, notes and introduction Nuno Ribeiro \& Cláudia Souza. New York: Contra Mundum Press, 2014.

26 BNP/E3, 15²- 65'; cf.: Pessoa, Philosophical, 7-8. 
(Página deixada propositadamente em branco.) 